\title{
TERRA Battery Thermal Control Anomaly - Simulation and Corrective Actions
}

\author{
Eric W. Grob ${ }^{1}$ \\ NASA Goddard Space Flight Center, Greenbelt, MD 20771
}

The TERRA spacecraft was launched in December 1999 from Vandenberg Air Force Base, becoming the flagship of NASA's Earth Observing System program to gather data on how the planet's processes create climate. Originally planned as a 5 year mission, it still provides valuable science data after nearly 10 years on orbit. On October $13^{\text {th }}, 2009$ at 16:23z following a routine inclination maneuver, TERRA experienced a battery cell failure and a simultaneous failure of several battery heater control circuits used to maintain cell temperatures and gradients within the battery.

With several cells nearing the minimum survival temperature, preventing the electrolyte from freezing was the first priority. After several reset attempts and power cycling of the control electronics failed to reestablish control authority on the primary side of the controller, it was switched to the redundant side, but anomalous performance again prevented full heater control of the battery cells. As the investigation into the cause of the anomaly and corrective action continued, a battery thermal model was developed to be used in determining the control ability remaining and to simulate and assess corrective actions. Although no thermal model or detailed reference data of the battery was available, sufficient information was found to allow a simplified model to be constructed, correlated against pre-anomaly telemetry, and used to simulate the thermal behavior at several points after the anomaly. It was then used to simulate subsequent corrective actions to assess their impact on cell temperatures.

This paper describes the rapid development of this thermal model, including correlation to flight data before and after the anomaly., along with a comparative assessment of the analysis results used to interpret the telemetry to determine the extent of damage to the thermal control hardware, with near-term corrective actions and long-term operations plan to overcome the anomaly.

$\begin{array}{ll}\text { Nomenclature } \\ A-h r & =\text { amp-hour, a measure of battery capacity } \\ B B A T & =\text { Bay Battery } \\ H C E & =\text { Heater Control Electronics } \\ M M O D & =\text { Micro-Meteorite and Orbital Debris } \\ P B A T & =\text { PEM Battery } \\ P E M & =\text { Power Equipment Module } \\ P W M & =\text { Pulse Width Modulation } \\ U V & =\text { Ultraviolet } \\ I R & =\text { Infrared }\end{array}$

\footnotetext{
${ }^{1}$ Staff Engineer, Thermal Engineering Branch, Applied Engineering Directorate, M/S 545, non-member. 1 American Institute of Aeronautics and Astronautics
} 


\section{Introduction}

T

HE TERRA battery consists of 108 50A-hr nickel-hydrogen cells arranged on two separate panels (54 cells each) to provide $120 \mathrm{~V}$ bus voltage. One panel is part of the Power Equipment Module (PBAT) and the other is a standalone panel mounted to the propulsion bay of the spacecraft bus (BBAT) as shown in Figure 1. All cells are mounted in "three-packs" with 3 cell/sleeve assemblies mounted to a common base (Figure 2), which are then mounted to the honeycomb radiator panel. These "T-shaped" bases allow tight packaging of the cells (Figure 3). Each battery is enclosed in an EMI cover and is thermally isolated (MLI and low conductivity kinematic mounts)



from the interior of the spacecraft. The exterior of the panel is also blanketed around the cell footprints, leaving the radiator area as the total of the base plate "footprint" areas. Flying in a nominal 10:30AM (sunsynchronous) descending node orbit, the $+Y$ side never receives direct solar incidence, so environmental heating is from albedo and Earth IR only. Each cell has a single heater with intertwined primary and redundant $5760 \mathrm{ohm}$ elements that receive voltage from the HCE $(120 \mathrm{~V}$ PWM) or from the survival

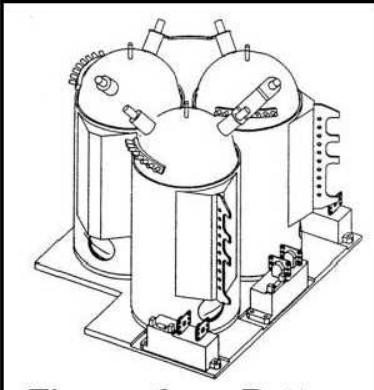

Figure 2 - Battery Cell Three-Pack thermostat (120V). PWM control is provided on a "six-cell" basis, by the HCE that compares the average of the cell temperatures (thermistor mounted on the sleeve) to the setpoint to determine the appropriate PW for the 6 cells in that heater circuit. The thermostats are located on the base plate and were designed with an $\mathrm{ON}$ setpoint that was selected to meet the temperature requirement at the thermistor, with approximately $3^{\circ} \mathrm{C}$ gradient between it and the thermistor.

Temperature requirements for the battery are:

$\begin{array}{ll}\text { Operational: } & -5^{\circ} \mathrm{C}<\mathrm{T}_{\text {OPER }}<+10^{\circ} \mathrm{C} \\ \text { Survival: } & -10^{\circ} \mathrm{C}<\mathrm{T}_{\text {SUR }}<+20^{\circ} \mathrm{C} \\ \text { Gradient: } & <3^{\circ} \mathrm{C} \text { (cell to cell) }\end{array}$

While the setpoint is commandable in $<0.2^{\circ} \mathrm{C}$ increments, the baseline setpoint of $-5.0^{\circ}<\mathrm{T}_{\mathrm{SET}}<-1.0^{\circ} \mathrm{C}$ has been used since launch. During the development phase, the workhorse BBAT, a prototype unit, was thermal balance tested $^{1}$. And information from that thermal test report was used in developing the thermal model for this anomaly investigation.

\section{Anomaly and Investigation}

Following a normally scheduled inclination adjustment maneuver, where the spacecraft is yawed from its normal science orientation to allow thruster firings to adjust for orbit inclination drift, telemetry indicated a voltage spike in cell $\# 50$, (BBAT) along with cooling of many of the neighboring cells. Telemetry also indicated that 5 of the BBAT heater zones (Side A - Groups 4, 5, 7, 8, and 9) were being commanded to provide maximum power, yet temperatures were still falling to near freezing temperature for the cell electrolyte, as shown in Appendix 3. Initial thoughts were that this resembled a similar anomaly that occurred only a few weeks prior (Day $249-$ September $6^{\text {th }}$, 2009), when the operational heater control was lost. But that anomaly was quickly resolved with a simple reset of the HCE. For this latest anomaly, the mission operations recovery effort again attempted a simple reset, then power cycle, of the HCE, but to no avail. The decision was then made to switch to Side-B of the HCE. After a few orbits data had been assessed, early discussions surmised that, based on telemetry plots, in conjunction with the loss of cell \#50, both survival and operational (Side-B) heater functions for Groups 4, 5, 8, and 9 had also failed. Even with transient temperature plots of all cells, along with the PW for each heater group, it wasn't clear whether all heaters 
in a group had failed, or only some. A thermal model was needed to help determine which operational and/or survival circuits/heaters were still working and to simulate subsequent changes before implementation.

\section{Model Development}

Constructing a thermal model of a battery typically is usually an elaborate effort, using detailed drawings of the machined parts. During the assembly and development of TERRA, a detailed thermal model had been completed and correlated with a BBAT thermal balance test [Ref. 1]. But ten years after launch, most detailed documentation, including the thermal model, had been archived and was not readily available. The battery CDR package and the BBAT CDR thermal analysis report were found and provided some key information.

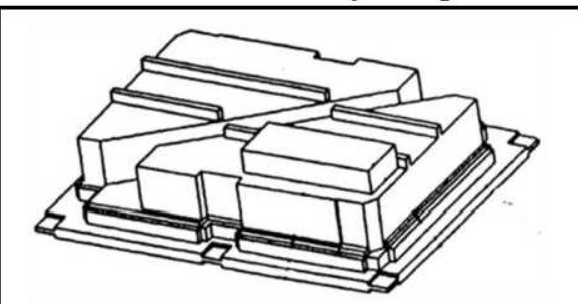

(a) BBAT EMI Cover (MLI not shown)

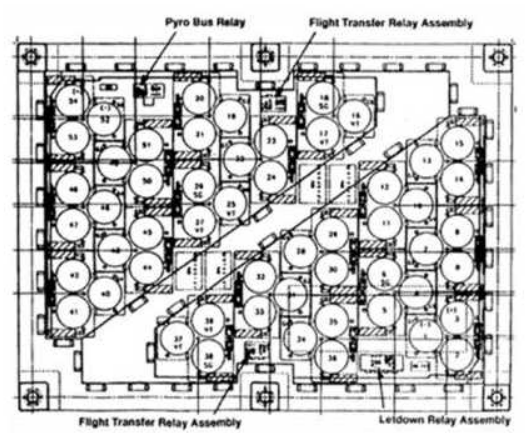

(b) BBAT Cell Arrangement

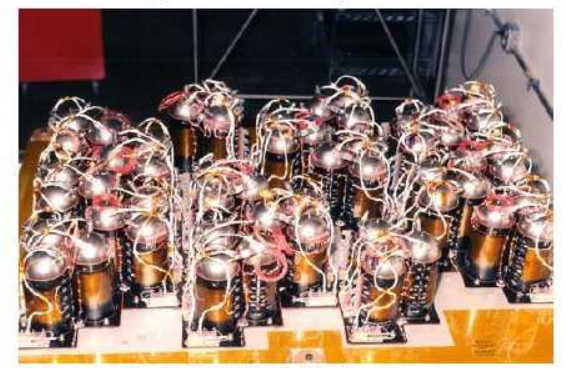

Figure 3. BBAT Cell Arrangement.

For the purposes of this investigation, a simple model that represented the telemetry and heater control functionality would suffice, and it was understood that this model could not reproduce the small gradients throughout the panel and that accuracy was not necessary. This model would be "benchmarked" using telemetry from pre-anomaly conditions and post-anomaly behavior, to be useful in assessing recovery efforts. Normal correlation criteria wouldn't necessarily be achievable, but the goal was to match the temperatures within $2{ }^{\circ} \mathrm{C}$ and heater power within $5 \%$.

Based on experience, the critical parts of a battery model are the thermal capacitance of the cell/sleeve, the conductive path from the cell to the radiator outer facesheet, and the cell dissipation. Initially, a simple one cell model (Figure 4) was developed with 5 nodes, using information from the BBAT documentation. Some details of this hardware were found in the report generated from the BBAT thermal vacuum testing completed almost 15 years prior to this anomaly. A thermal analysis report from the cell manufacturer and review notes by the author provided an authentic representation of the battery cell and the cell-sleeve interface. Pertinent details of the honeycomb radiator were found in the BBAT test report.

By design, the thermal environment for the BBAT in this sun-synchronous orbit is benign. The eclipse is nearly constant, varying between 32.8 and 34.4 minutes and the incident environmental heat loads, calculated using Thermal Desktop, are also shown to almost constant (only $4 \%$ change) over the

limited beta angle range $\left(-27^{\circ}<\beta<-17^{\circ}\right)$ for the August through October

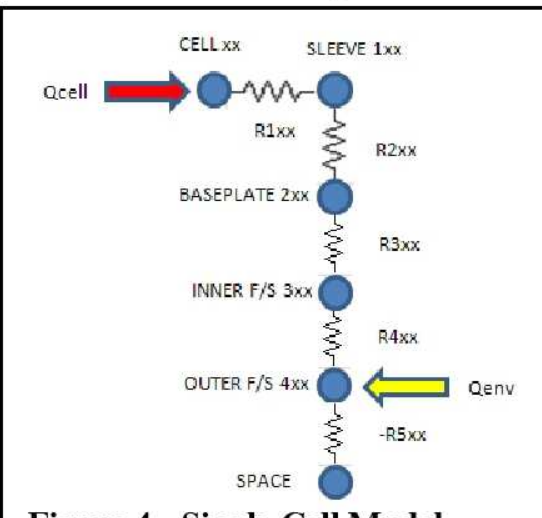

Figure 4 - Single Cell Model 2009 timeframe. Appendix 1 summarizes cell dissipation and environmental heating data for this study. This simple model was used to provide an initial transient correlation to the average of the 54 BBAT cell temperatures and orbit average heater power using pre-anomaly (Day 224/2009) telemetry. This was done to ensure cell and environmental heating data was representative of the actual conditions the resulting temperatures were $-3.5^{\circ}<\mathrm{T}_{\mathrm{CELL}}<-1.8^{\circ} \mathrm{C}$ and $47 \%$ heater duty cycle which essentially matched the telemetry.

The single cell model was then replicated 54 times, adding in the necessary lateral baseplate and facesheet conductive links, to represent the entire BBAT. Since the cells are mounted on the inside of the radiator panel, covered with an aluminum EMI shield, and isolated with thermal blankets and low conductivity kinematic mounts from the spacecraft, the spacecraft interface was considered adiabatic. Cell-cell radiation couplings were not included since the temperature difference was considered small enough that this would have a negligible effect. 


\section{Correlation Results}

Much like thermal vacuum test correlation, this effort required stable data to compare the model predicts to. Despite the numerous configuration changes being done to maintain the health of the battery, a few cases were available to correlate to.

$\begin{array}{ccl}\frac{\text { Date }}{\text { DO/12/2009 }} & \frac{\text { DOY }}{224} & \text { Action } \\ \text { Correlation \#1 (Pre-anomaly) } \\ \text { 10/13/2009 } & 286 & \text { Anomaly [16:23 GMT] } \\ \text { 10/13/2009 } & 286 & \text { Performed Battery Master Reset } \\ \text { 10/13/2009 } & 286 & \text { Power cycled HCE5A Side A } \\ 10 / 16 / 2009 & 289 & \text { Switched to HCE5A Side B } \\ 10 / 30 / 2009 & 303 & \text { Changing VT and C/D } \\ \text { Correlation \#3 }\end{array}$

\begin{tabular}{|c|c|c|c|c|c|c|c|c|c|}
\hline \multicolumn{10}{|c|}{ Table 1 - Day $224 O_{H T R}$ Telemetry } \\
\hline BBAT $\mathrm{Ht}$ & \multicolumn{3}{|c|}{ Avg Temperature $\left({ }^{\circ} \mathrm{C}\right]$} & \multicolumn{5}{|c|}{ Pulse Width Signal $(\%)$} & \multirow[b]{2}{*}{ Qhtr ranl } \\
\hline Group & Min & Max & Avg & Min & Max & Avg & delta & AvgRank & \\
\hline 1 & -4.1 & -1.4 & -2.7 & 11.7 & 63.7 & 42.7 & $52 \%$ & 8 & \\
\hline 2 & -4.1 & -1.4 & -2.8 & 12.5 & 65.6 & 44.3 & $53 \%$ & 6 & \\
\hline 3 & -4.3 & -1.7 & -3.0 & 19.5 & 71.9 & 50.8 & $52 \%$ & 4 & \\
\hline 4 & -4.8 & -1.9 & -3.4 & 25.0 & 77.3 & 55.6 & $52 \%$ & 3 & \\
\hline 5 & -4.7 & -1.9 & -3.3 & 19.9 & 70.3 & 50.0 & $50 \%$ & 5 & \\
\hline 6 & -4.5 & -1.9 & -32. & 27.7 & 84.8 & 58.8 & $57 \%$ & 1 & coldest \\
\hline 7 & -4.2 & -1.7 & -3.0 & 25.0 & 80.5 & \begin{tabular}{|l|}
57.4 \\
\end{tabular} & $55 \%$ & 2 & \\
\hline 8 & -4.1 & -1.5 & -2.8 & 12.5 & 67.2 & 44.0 & $55 \%$ & 7 & \\
\hline & & & & & & & & & \\
\hline Min & -4.8 & -1.9 & -3.4 & 11.7 & 63.7 & 42.2 & $50 \%$ & & \\
\hline Max & -3.9 & -1.4 & 2.7 & 27.7 & 84.8 & 58.8 & $57 \%$ & & \\
\hline Avg: & -4.3 & -16 & -30 & 18.4 & 71.7 & 49.5 & $53 \%$ & & \\
\hline
\end{tabular}

This expanded model was then correlated against the individual Day 224 cell temperatures and heater power duty cycles (Table 1). The correlation results (Figure 5) are plotted (3D contour) using orbit average cell temperatures. To help assess model accuracy, the error between the predictions and telemetry was also plotted. Note the green "trough" in the telemetry plot follows the structural cutout in the cell packaging. Likewise, the model predictions show the same feature, although the spatial gradient is slightly less pronounced. Overall, the model matched the preanomaly temperature telemetry within $<0.14^{\circ} \mathrm{C}$ ($\left.0.98^{\circ}<\Delta \mathrm{T}<0.61^{\circ} \mathrm{C}\right)$ including $82 \%$ of the nodes matching within $+/-0.5^{\circ} \mathrm{C}$ and the operational heater duty cycle were $49 \%<\mathrm{PW}<58 \%$ (vs $42 \%<\mathrm{PW}<57 \%$ in telemetry), which was considered acceptable.

The earlier HCE anomaly (Day 249) resulted in the loss of operational heater control,
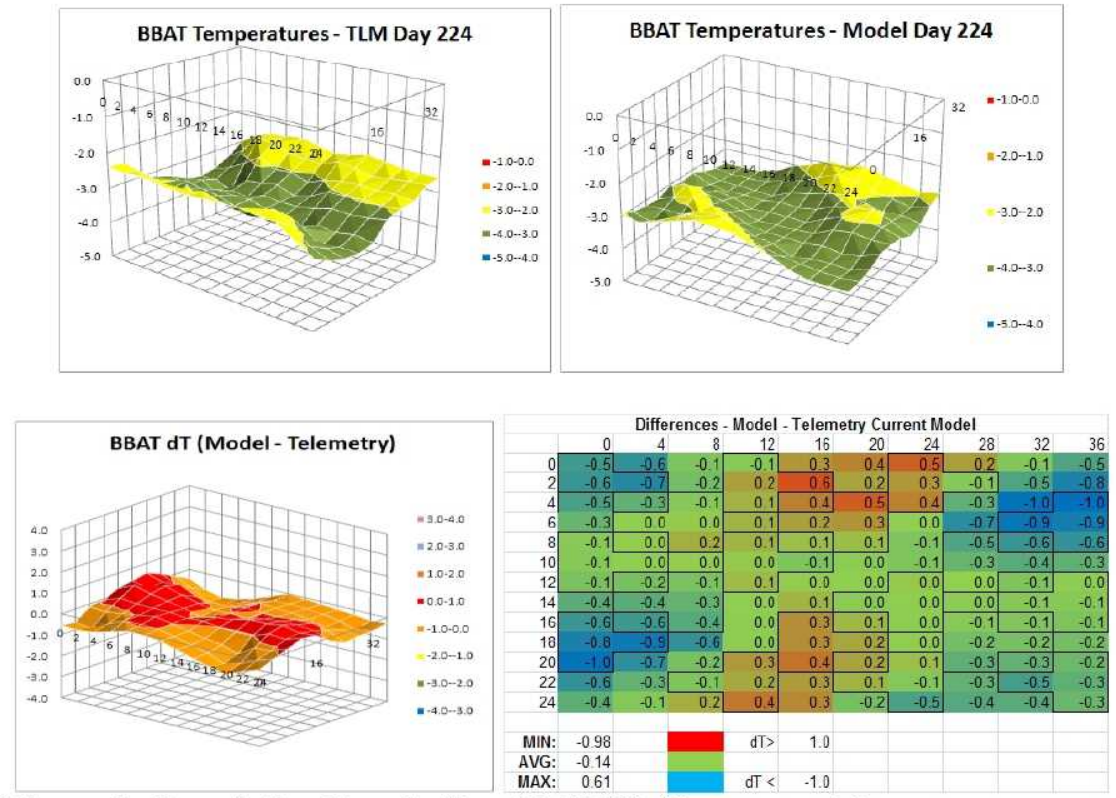

Figure 5. Correlation Results Day 224/2009 (Pre-anomaly). with the cells cooling to the survival thermostat setpoint. This telemetry, along with the telemetry from the Day 286 anomaly, is plotted together in Figure 6. A comparison of the two shows that, while the thermostats came on in the earlier anomaly, the data from the latest anomaly does not indicate that they activated. Using the model to simulate Day 249 shows the same temperature increase when the thermostats close then cooling after opening, which confirms that the Group 4, 5, 8, 9 survival heater circuits are not working, at least as designed.

The initial development of the thermal model spanned several days during which various changes were made to the VT curves and C/D ratios to allow the battery to generate more heating during the charge cycles. It wasn't until Day 303 that the configuration was stable enough to provide some correlation data. The failure of cell $\# 50$ was simulated by zeroing out the dissipation for that cell and the operational heater control logic was turned off for the

\begin{tabular}{|c|c|c|c|c|c|c|c|c|c|}
\hline \multicolumn{10}{|c|}{$3 \mathbf{Q}_{\text {HTR }} \mathrm{Te}_{\mathrm{C}}$} \\
\hline \multirow{2}{*}{$\begin{array}{l}\text { BBAT Htr } \\
\text { Group }\end{array}$} & \multicolumn{3}{|c|}{ Avg Temperature $\left({ }^{\circ} \mathrm{C}\right)$} & \multicolumn{5}{|c|}{ Pulse Width Signal (\%) } & \multirow[b]{2}{*}{ Qhtr rank } \\
\hline & Min & $\operatorname{Max}$ & Avg & Min & $\operatorname{Max}$ & Avg & delta & AvgRank & \\
\hline 1 & -3.9 & -1.6 & -2.8 & 15.2 & \begin{tabular}{|c|}
67.2 \\
67
\end{tabular} & \begin{tabular}{|c|}
409 \\
45.3
\end{tabular} & 520 & $\frac{9}{9}$ & warmest \\
\hline 2 & -4.1 & -1.7 & -3.0 & 19.1 & \begin{tabular}{|l|}
70.3 \\
\end{tabular} & \begin{tabular}{|c|}
49.5 \\
\end{tabular} & 51.2 & 8 & \\
\hline 3 & $-5.0^{\circ}$ & $-2.6^{p}$ & -3.9 & 41.4 & \begin{tabular}{|l|}
93.4 \\
\end{tabular} & 72.5 & 520 & 6 & \\
\hline 4 & -11.8 & $-8.8^{\circ}$ & 10.4 & 100.0 & 100.0 & 100.0 & 0.0 & 1 & oolest \\
\hline 5 & -9.6 & -674 & -8.3 & 100.0 & 100.0 & 100.0 & 00 & 1 & coolest \\
\hline 6 & -5.07 & $-2.33^{\prime \prime}$ & $-3.8 \mid$ & 39.1 & $\mid$\begin{tabular}{|l|}
$\mid 94.5$ \\
\end{tabular} & $\mid 69.9$ & 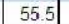 & 7 & \\
\hline 7 & $-4.9^{\circ}$ & $-2.3^{3}$ & -3.7 & 50.4 & \begin{tabular}{|l|l|}
99.6 \\
\end{tabular} & 89.2 & 49.2 & 5 & \\
\hline 0 & 10.2 & 7.1 & -8.8 & 100.0 & 100.0 & 100.0 & 0.0 & 1 & coolest \\
\hline 9 & -11.7 & $-8.9^{\prime}$ & 10.4 & 100.0 & 100.0 & 100.0 & 0.0 & 1 & coolest \\
\hline Min & -11.8 & -8.9 & 10.4 & 15.2 & 67.2 & 45.3 & 0.0 & & \\
\hline $\operatorname{Max}$ & -3.9 & -1.6 & -2.8 & 100.0 & 100.0 & 100.0 & 55.5 & & \\
\hline Avg: & -7.4 & -4.7 & -6.1 & 62.8 & 91.7 & 80.7 & 28.9 & & \\
\hline
\end{tabular}


suspected failure of heater groups 4, 5, 8, and 9. The orbit average comparison (Figure 7a) shows the orbit average model temperatures closely match the telemetry, suggesting that either the thermostats are working, or something else was affecting the heat balance of the BBAT. The model was able to match this telemetry set with an average error of $<0.5^{\circ} \mathrm{C}\left(-3.5^{\circ}<\Delta \mathrm{T}<+1.5^{\circ} \mathrm{C} ; 78 \%\right.$ of the nodes within $1{ }^{\circ} \mathrm{C}$ error $)$ and $56 \%<\mathrm{PW}<100 \%$ at an average of $81 \%$, which compares well with the telemetry values in Table 2 [Note: the $100 \%$ duty cycles shown for Groups $4,5,8,9$ are calculated by the model for, but not applied to, the failed heater circuits, which is the same as the flight telemetry]. However, if the Group 04, 05, 08, 09 survival heaters are were disabled, the model now predicts the cold region as being much colder than the data (Figure $7 \mathrm{~b}$ ) with $-19.4^{\circ}<\Delta \mathrm{T}_{\mathrm{ERROR}}<1.8^{\circ} \mathrm{C}$. Since the thermostat operation had been demonstrated just a few weeks earlier during the HCE anomaly, and this anomaly telemetry did not follow the ON/OFF pattern seen then, these thermostat survival heaters are believed to be non-functional, but something else must have affected the energy balance of the BBAT to keep the temperatures from being as cold as suggested by the correlated model.

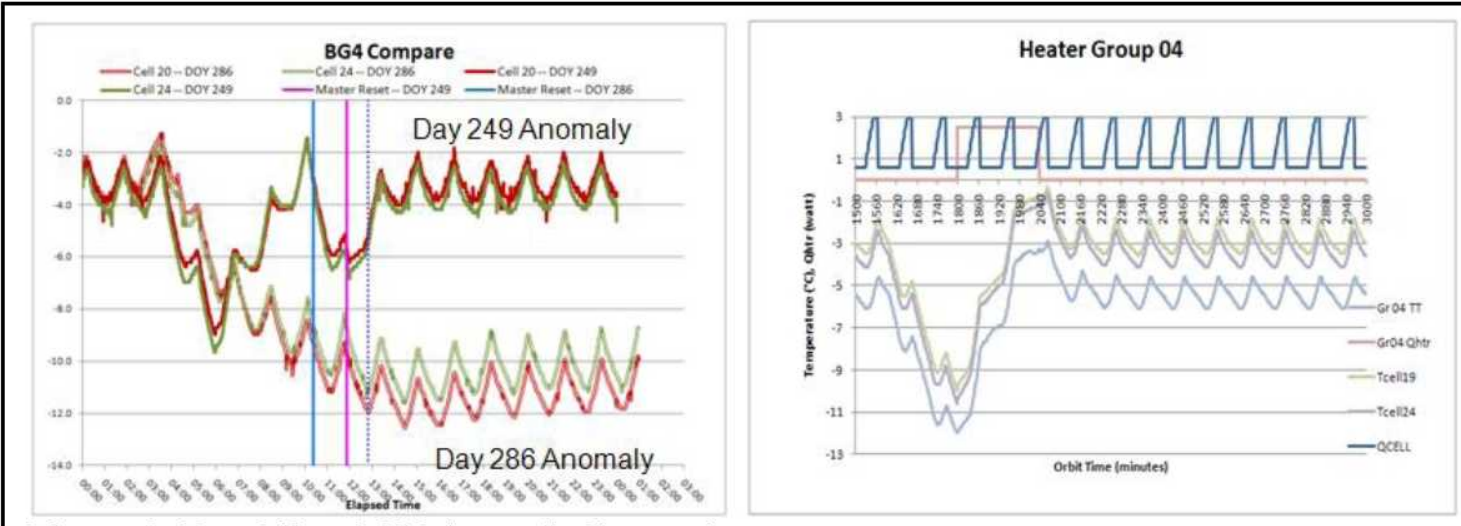

Figure 6 - Day 249 and 289 Anomaly Comparison

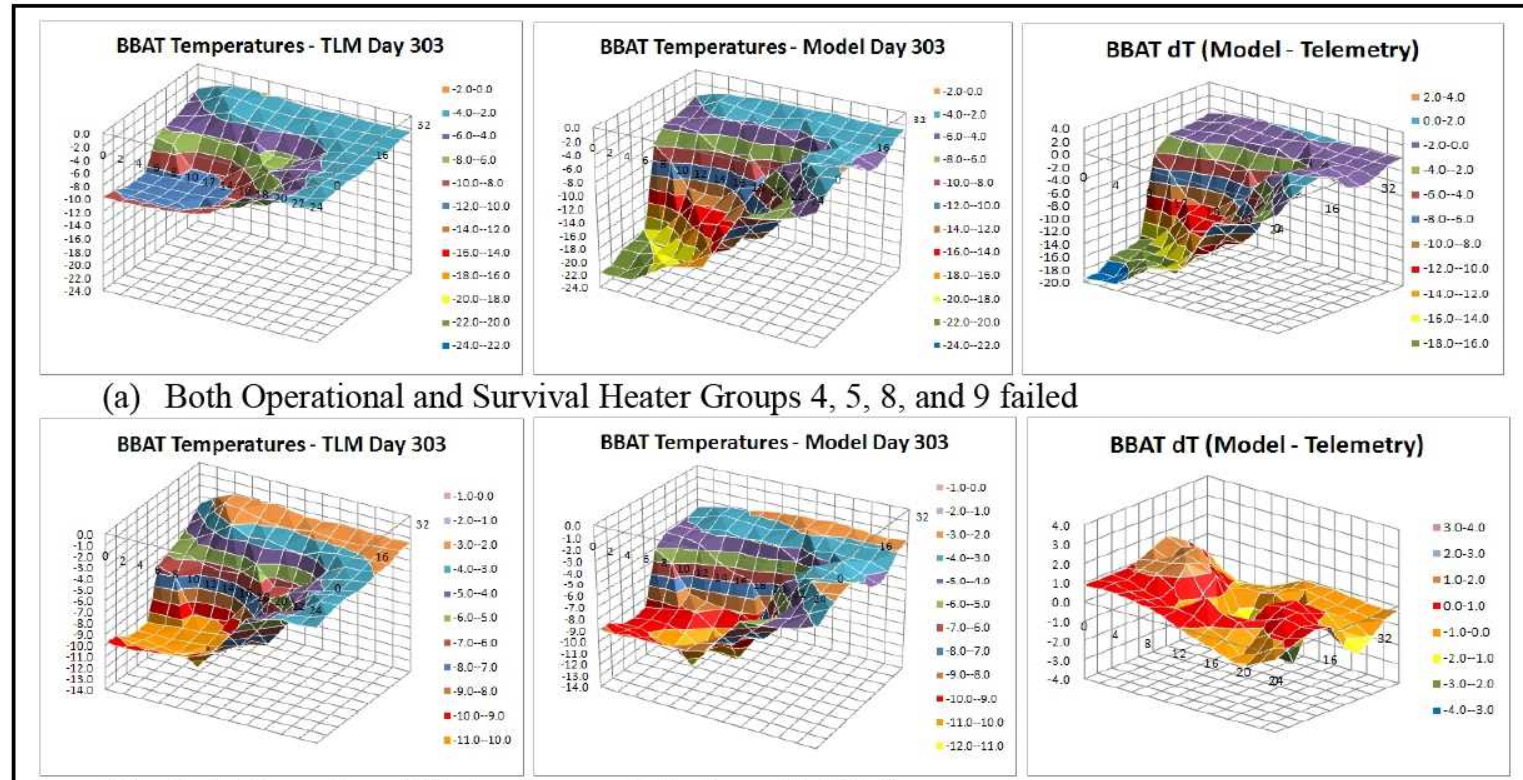

(b) Only Operational Heater Groups 4, 5, 8, and 9 failed

Figure 7. Correlation Results - Dav 303/2009

Given that the anomaly was believed to have been caused by an MMOD strike, the subsequent changes to the thermal configuration could have impacted the heater power harness in the vicinity and may also have included changes to the MLI and radiator effectiveness, cause by the impact itself, or collateral effects. The venting of the 700-800 psi battery cell may have temporarily pressurized the BBAT EMI compartment sufficiently to cause the interior MLI over the EMI cover to come loose and allow some heat gain from the somewhat warmer spacecraft 
interior. Some degradation of the radiator effectiveness due to the MMOD (or shrapnel) impact may also have occurred. While this may never be conclusively known, the model was utilized to assess the effect of these two possibilities.

Because each triangular EMI cover is so large $\left(\sim 9 \mathrm{xA}_{\text {baseplate }}\right.$ or $\left.750 \mathrm{in}^{2}\right)$, a simple calculation conservatively shows $9 \mathrm{~W}$ could easily be transferred into the BBAT from a $0^{\circ} \mathrm{C}$ spacecraft interior if the MLI were removed or dislocated. This would represent $0.33 \mathrm{~W}$ per cell, or about $13 \%$ of the operational heater duty cycle, which is significant. Figure 8 shows the associated correlation plots for this scenario with an overall temperature error $\Delta \mathrm{T}<-0.21^{\circ} \mathrm{C}\left(-3.1^{\circ}<\right.$ $\Delta \mathrm{T}_{\text {ERROR }}<2.5^{\circ} \mathrm{C}$ ) with operational heater duty cycles of $55 \%<\mathrm{PW}<100 \%$ (avg $79 \%$ ) versus $45 \%<\mathrm{PW}<100 \%$ (avg $81 \%$ ) indicated in the telemetry.

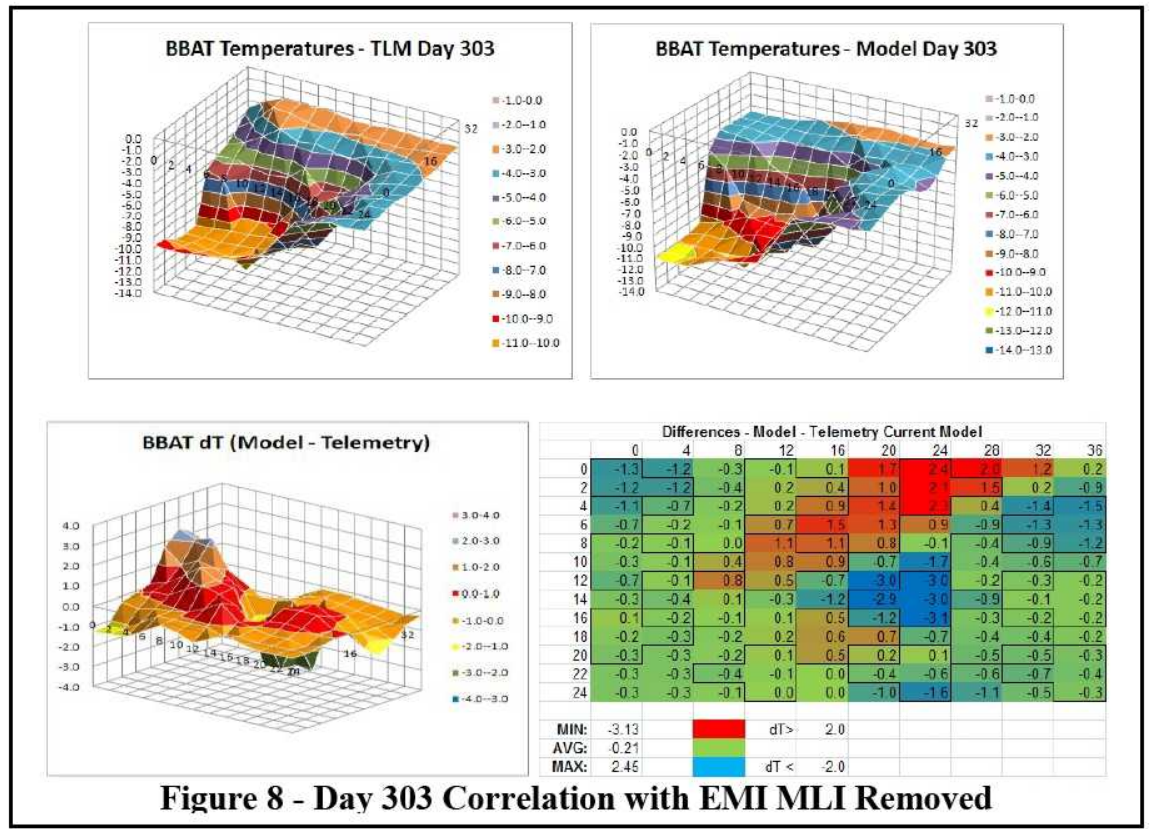

Likewise, Figure 9 shows the associated correlation plots for a degraded radiator effectiveness scenario where the inner-outer facesheet coupling was degraded by $20 \%$ in the region of the MMOD strike showing an overall temperature error $\Delta \mathrm{T}<-0.41^{\circ} \mathrm{C}\left(-3.0^{\circ}<\Delta \mathrm{T}_{\text {ERROR }}<1.6^{\circ} \mathrm{C}\right)$ with operational heater duty cycles of $55 \%<\mathrm{PW}<100 \%$ (avg $80 \%$ ) versus $45 \%<\mathrm{PW}<100 \%$ (avg $81 \%$ ) indicated in the telemetry. Again, the $100 \%$ duty cycles in these results are calculated for, but not applied to, the failed heater circuits.

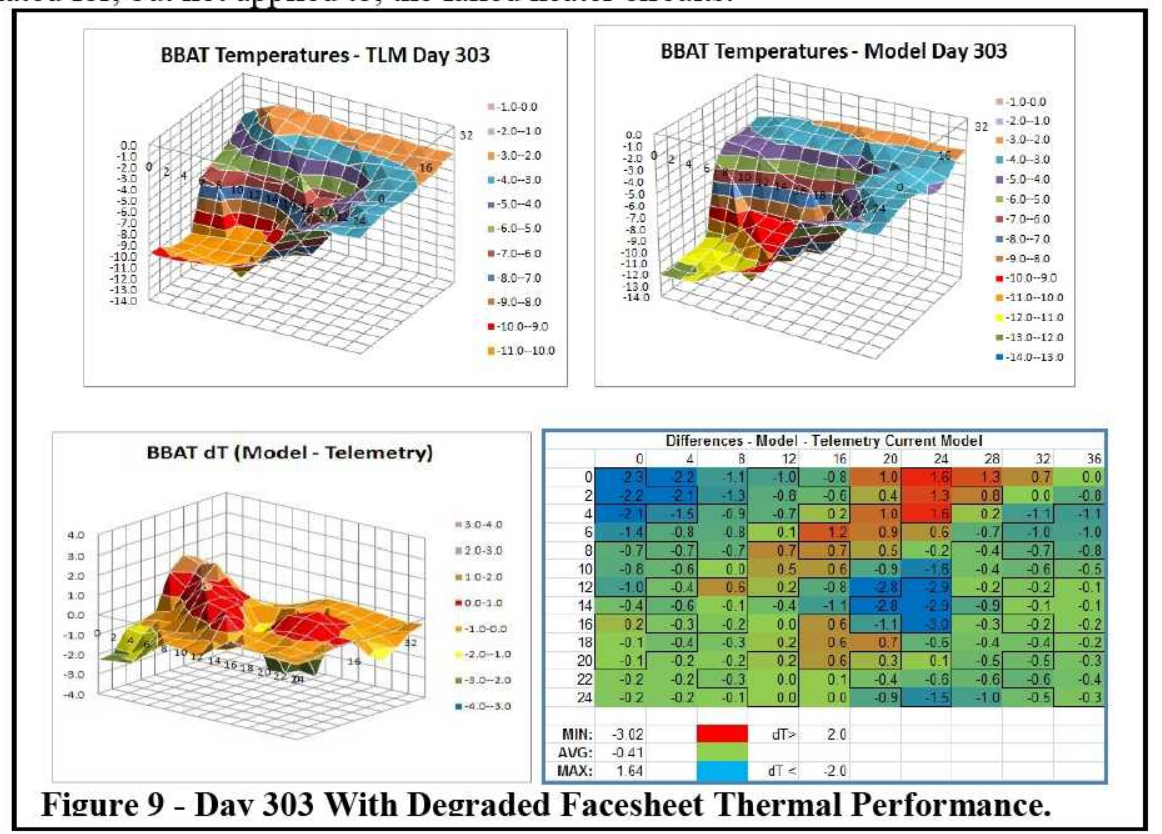

6

American Institute of Aeronautics and Astronautics 


\section{Conclusion}

This model was developed to help determine the status of the TERRA battery thermal hardware after an apparent MMOD impact that vented one of the 108 cells and collaterally disabled much of the heater control capability. Following this mission threatening anomaly, the assembled engineering tiger team was able to quickly understand the situation and prescribe a correct set of changes, using the surviving thermal control capability and creative charging manipulation to place the BBAT into a stable, if not desirable, temperature regime while a more detailed review was undertaken, including thermal model development. The lack of detailed information on the BBAT design and thermal models did not prevent a useful thermal model from being developed to assess the anomaly and be helpful as a "test bed" for operational changes. After development, using only basic information gathered from project reports generated more than 15 years earlier, the model was exercised to successfully simulate the preanomaly and post-anomaly data to fairly accurate criteria.

Using some broad assumptions, the model was used to assess the failure and possible solutions. Since then, it has been continued to be refined and updated. Although there is no conclusive evidence of some of the assumptions simulated to achieve good correlation in the post-anomaly analysis, these scenarios could easily have occurred due to the MMOD impact and subsequent high pressure venting.

Unlike the original models, which couldn't be located for this effort, this model is currently maintained with the Goddard Space Flight Center Mission Operations Team, as well as within the Applied Engineering Directorate for use in the future, if needed. 
Appendix 1- Environment \& Cell Heating Data
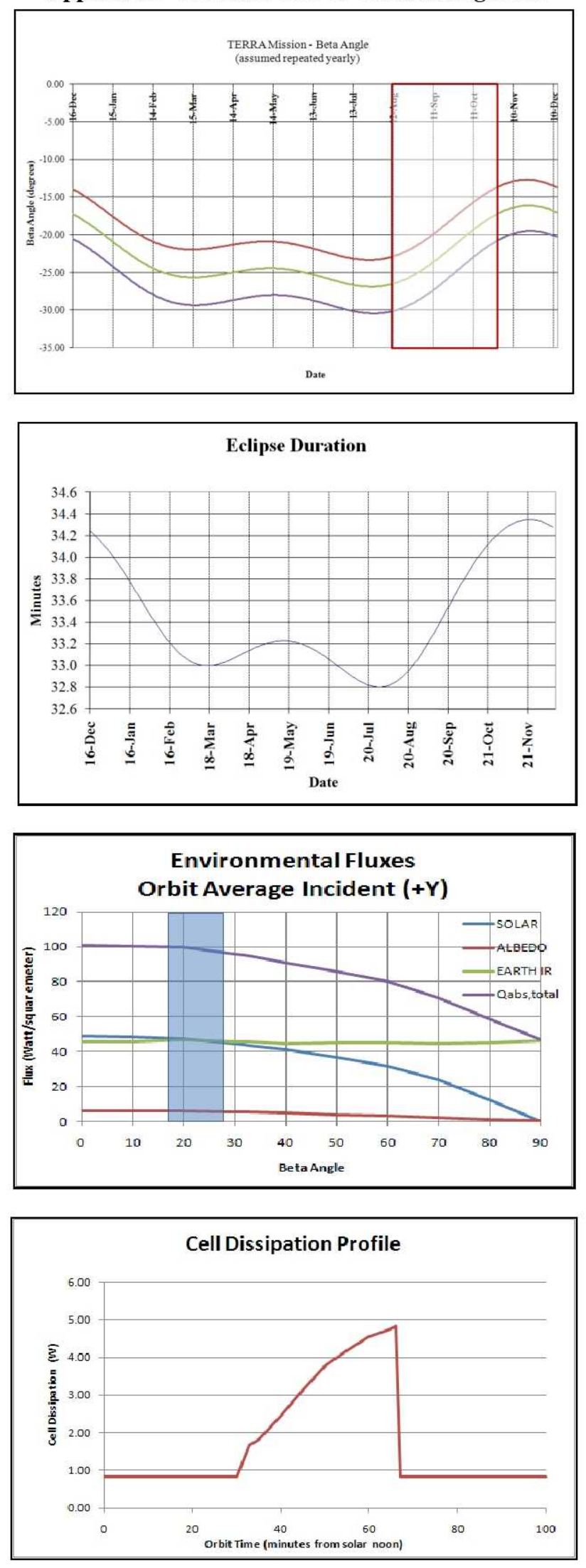

8

American Institute of Aeronautics and Astronautics 
Appendix 2- Day 224 BBAT Temperature Telemetry
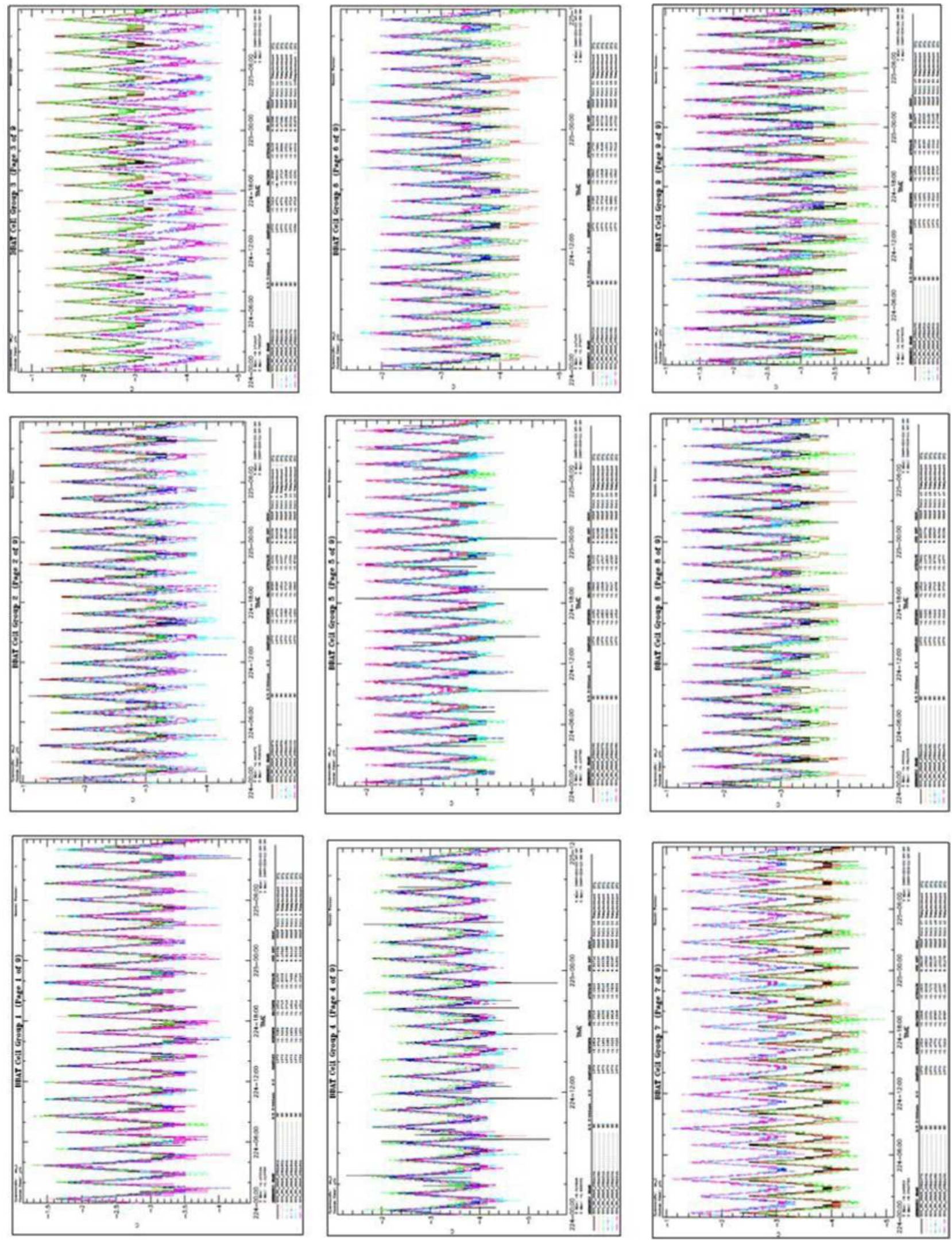

9

American Institute of Aeronautics and Astronautics 
Appendix 3 - Anomaly Telemetry

Day 2009-286 PW Telemetry Showing Cell Heaters Saturating
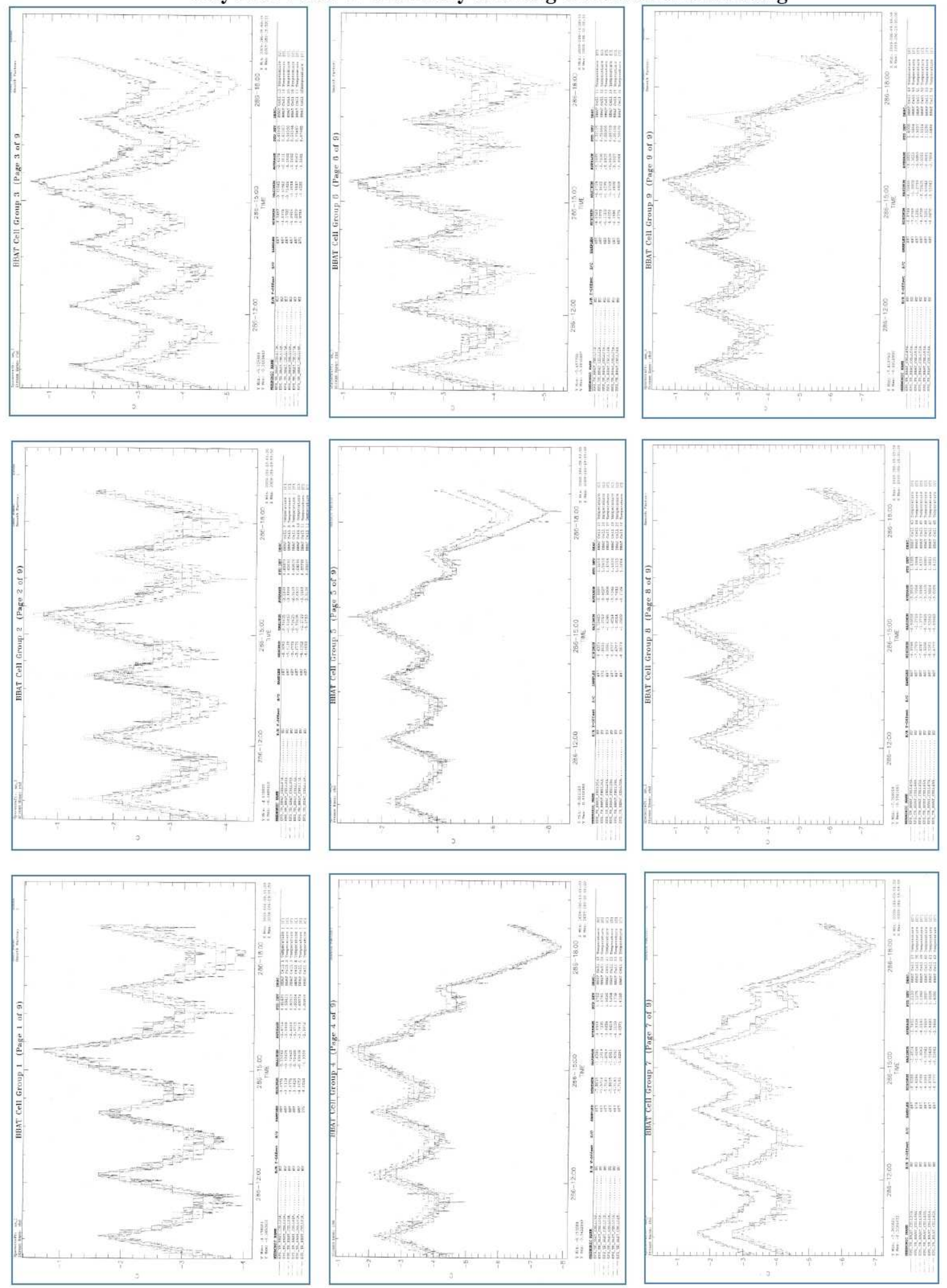
Appendix 3 - Anomaly Telemetry (continued)

Day 2009-286 Temperature and PW Telemetry Showing Cell Cooling
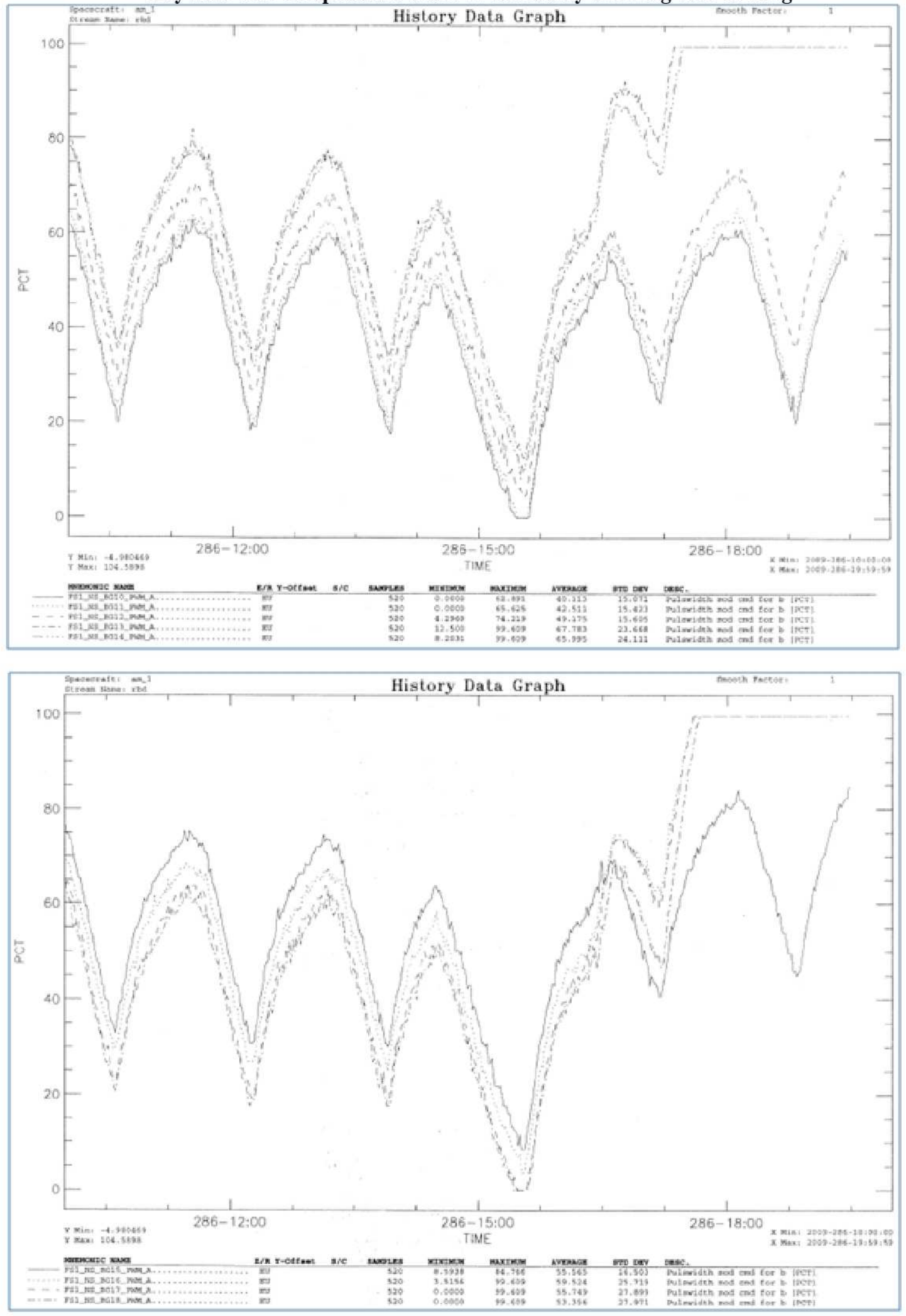

11

American Institute of Aeronautics and Astronautics 


\section{Acknowledgments}

The author gratefully acknowledges the input and assistance of the Mission Operations Team located at NASA GSFC in providing the data used for this development and correlation effort and the insight provided by Dick Quinn, former TERRA project manager, of Lockheed-Martin.

\section{References}

${ }^{1}$ Grob, E. W., Chalmers, D. R., Bennett, C. W., "Thermal Design \& Verification of the EOS-AM1 Nickel Hydrogen Batteries," IECEC Intersociety Energy Conversion Engineering Conference, CP97439, Vol. 1, IECEC, Honolulu, HI, 1997, pp. 207-212 